\title{
Numerical simulation of a discontinuous gallery lining's behavior, and its interaction with rock
}

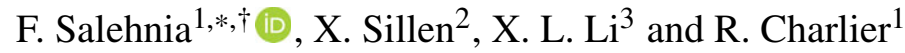 \\ ${ }^{1}$ Département ArGEnCo, Université de Liège, Liège 4000, Belgium \\ ${ }^{2}$ Belgian Agency for Nuclear Waste and Fissile Materials (ONDRAF/NIRAS), Brussels 1210, Belgium \\ ${ }^{3}$ European Underground Research Infrastructure for Disposal of Nuclear Waste in Clay Environment \\ (EIG EURIDICE), Mol 2400, Belgium
}

\begin{abstract}
SUMMARY
Deep excavation in some geological media needs lining of the gallery. This could limit the extent of the so-called excavation damaged zone and the resulting convergence of the material due to tunneling. Boom clay, the reference potential host rock in Belgium for disposal of high-level radioactive waste, is one of these media for which lining of the gallery walls is essential. A correct simulation of the lining behavior in the course of the excavation process, where the rock comes into contact with the lining, and in the long term, remains a significant challenge in analysis of the whole coupled phenomena of rock in interaction with the lining. This study aims to numerically model the lining behavior. The main objective is to develop a model that could realistically simulate the behavior of a discontinuous lining made of concrete segments. We propose to numerically analyze the response of the blocks in contact with each other and in interaction with rock, with the use of zero-thickness interface elements. To validate the developed model and a proposed approach, a particular analysis compares the obtained results with the available in situ measurements. This study then discusses the deficiency of the simplistic model that considers a continuous lining. In addition, regarding the contact mechanism on the interface between the rock and the lining, the obtained results demonstrate an interesting relation between the contact phenomena and the shear banding within the rock around the gallery. Copyright (C) 2017 John Wiley \& Sons, Ltd.
\end{abstract}

Received 14 February 2016; Revised 23 February 2017; Accepted 27 February 2017

KEY WORDS: discontinuous lining; concrete segments; Boom clay; interface; contact pressure; shear bands

\section{INTRODUCTION}

The contribution of nuclear power in some industries, such as global electricity generation, inevitably results in the production of some amount of high-level nuclear waste. One possible solution, within the long-term management of these wastes, is storage in deep geological media. The host formation should have favorable properties that ensure adequate isolation from man and environment. Boom clay formation, located in the north of Belgium, is considered as the reference potential host rock for this purpose, considering its low hydraulic conductivity, plasticity, and self-sealing capacity.

Deep excavation of underground galleries in some geological media, namely plastic Boom clay, needs lining of the gallery. The lining could be essential to limit the resulting convergence of the rock on the gallery side walls and to decrease the extent of the so-called excavation damaged zone (EDZ) $[1,2]$. The EDZ is a zone with significant irreversible deformation, macro-fracturing and

\footnotetext{
*Correspondence to: F. Salehnia, Département ArGEnCo, Université de Liège, Allée de la Découverte 9, Liège 4000, Belgium.

${ }^{\dagger}$ E-mail: f.salehnia@alumni.ulg.ac.be

Copyright (C) 2017 John Wiley \& Sons, Ltd.
} 
micro-fracturing, and important modifications to the rock's original properties, potentially resulting from excavation and stress redistribution.

The method considered for lining the galleries excavated through the Boom clay formation is the wedge-block technique. Discontinuous concrete segments are assembled to establish rings. These rings are then expanded against the excavated clay massif through insertion of one or more key segments [3].

Thence, a unique interest in analysis of the whole coupled phenomena from the excavation phase onward addresses the simulation of the lining behavior. The simplistic approach for modeling this complex excavation process in rock, in interaction with the lining, considers a continuous lining [4]. This paper first aims to demonstrate the deficiency provided though this simplification, with reference to an analysis of the in situ strain measurements in a gallery's lining, excavated in the Boom clay formation. As a result, a numerical model is developed proposing an approach to realistically simulate the long-term behavior of a discontinuous lining and the relative response of the segments in contact with each other. The modeling is performed through the finite element code LAGAMINE, developed at the Université de Liège [5, 6].

Analysis of the contact mechanism and relative deformation of the concrete segments of the lining, as well as their own response, are then addressed in this paper as the open issues of particular interest. The contact mechanism between the lining and the rock is analyzed in relation to the fracturing pattern within the clay in proximity to the gallery. These contact phenomena are proposed to be simulated through definition of zero-thickness interface elements. Moreover, the shear-induced fracturing, as frequently observed within the EDZ around the excavated galleries in Boom clay [7], is modeled numerically within the framework of a strain localization approach in shear band mode [4, 8-12]. These shear zones with localized plastic strain are supposed to give rise to the discontinuities in a progressive failure.

A large excavation problem in Boom clay host rock has been numerically studied in some previous works $[4,13,14]$. The latter reference has considered a simplified continuous lining for the excavated gallery that this simplification could cause some deficiencies in a correct presentation of the lining response, as already mentioned. Despite all the previous numerical works that concern the Boom clay behavior, the need for a correct understanding and a realistic prediction of the lining response and its relative phenomena through analysis of the whole problem is paramount. The main novelty of this paper is therefore addressed to fulfill this gap. In parallel, the results obtained from the developed model are to be checked against the corresponding in situ measurements of the lining in order to validate the proposed approach.

\section{THEORETICAL FORMULATION}

\subsection{Constitutive models: interface behavior}

Given the numerical simulation of a gallery excavation in Boom Clay, the interfaces features are focused on in this paper. These interfaces overall refer to the interface of the host rock and the concrete lining as well as the interfaces between the lining segments (Figure 1). The interface element is a powerful tool in modeling of such geometrical discontinuities within a finite element analysis [15]. Therefore, we propose modeling of these interface behaviors through introduction of hydro-mechanical interface elements.

From a conceptual point of view, the contact of two solids results in the generation of some restrictions on their displacement. This process then gives rise to the contact stresses on their interface, in the contact zone. Upon contact of two bodies, the contact constraints are considered to be activated, which then need to be ensured. These constraints are treated here using the penalty method as is frequently applied in finite element analysis of contact problems [16]. This method allows for some penetration of the bodies in contact (Figure 2). The corresponding penalty coefficient should be carefully introduced in the numerical model in order to minimize the penetration of the two bodies in contact. This should take place while the coefficient is not too large as it could impose an ill-conditioned numerical problem. Indeed, there are some limitations in increasing this coefficient. 


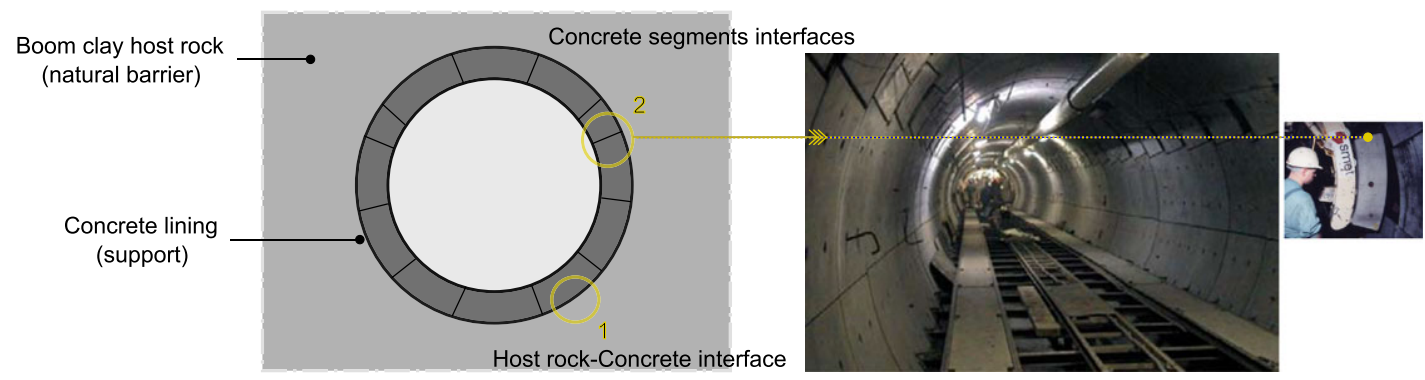

Figure 1. Schematic representation of the interfaces between the Boom clay host rock and the studied gallery's lining, and between the lining segments, in a section perpendicular to the gallery axis. The right image [3] shows a general view of the Connecting gallery lining (HADES Underground Research Laboratory, Mol, Belgium) beside a close-up of the emplacement of one segment of the lining, demonstrating its two corresponding interface boundaries with the adjacent segments.

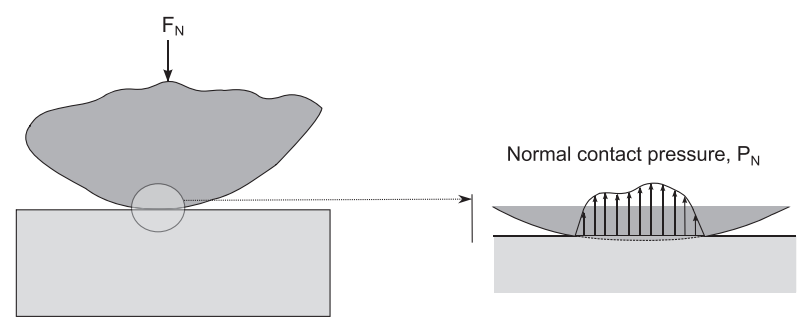

Figure 2. Conceptual representation of the penalty method on treatment of the normal contact constraint.

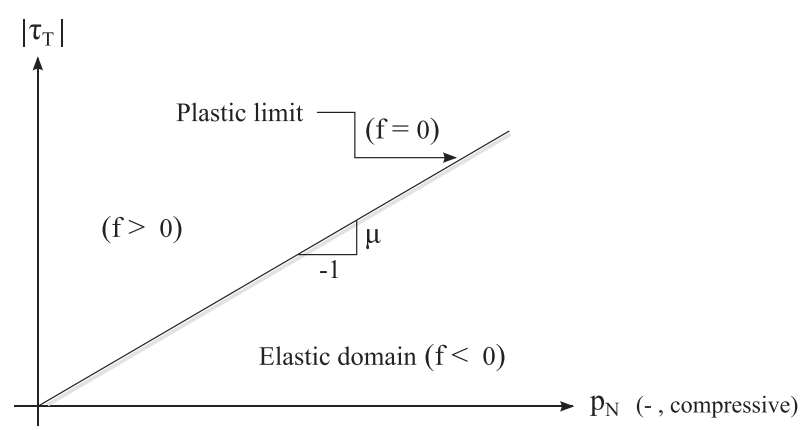

Figure 3. Representation of the Coulomb yield criterion.

The frictional contact problem is usually treated by a mean of the elasto-plasticity analogy [17]. Within this framework, upon contact of two bodies, the sticking phase is compared with the elastic state of contact behavior. Then, when in the course of evolutionary contact, the interface response meets the slipping condition, this is equivalent to an elasto-plastic state. The stick and slip states of the contact interface behavior are distinguished in our study via the Coulomb yield criterion, as the mechanical constitutive law for the contact problem:

$$
f=\left|\tau_{T}\right|+\mu p_{N}
$$

where $p_{N}$ and $\tau_{T}$ are the normal and tangential components of the contact stress vector, respectively, and $\mu$ is the Coulomb friction coefficient. Assuming two contacting bodies, if the interface stress state lies below the yield criterion (i.e., $f<0$; see Figure 3), this elastic domain corresponds to the sticking behavior. Then, when the threshold value in the modulus of the tangential stress is reached, that is, the stress state hits the yield criterion and $f=0$, the slip condition is met. 
(a)
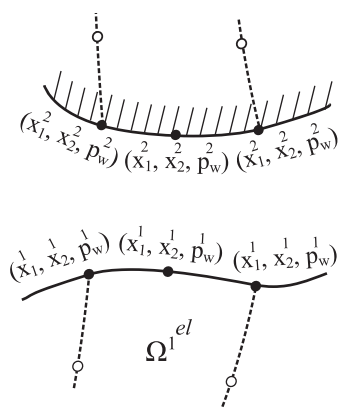

- Node

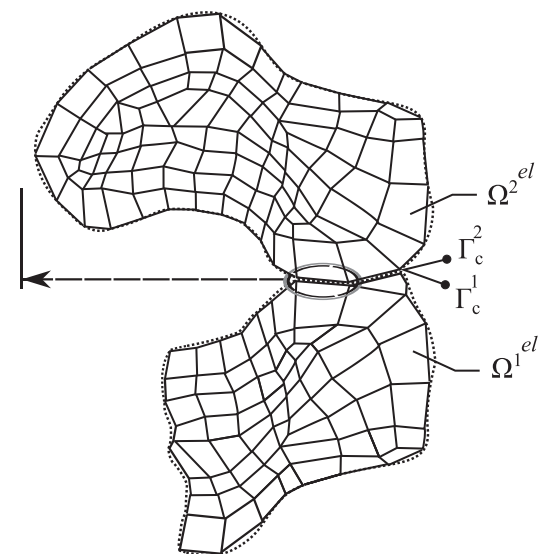

(b)

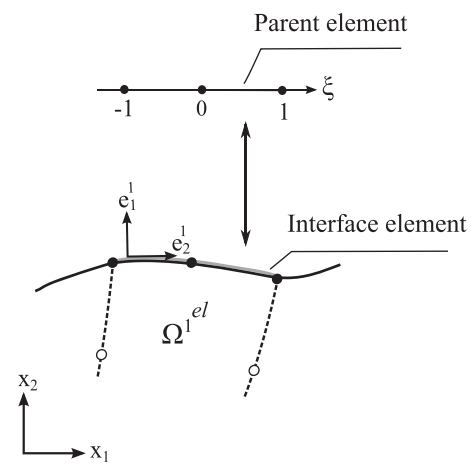

Figure 4. Parabolic three-node interface element. (a) Discretization description. (b) Interface element and corresponding parent element. $\left(e_{1}^{1}, e_{2}^{1}\right)$ are the local current basis on the interface surface $\Gamma_{c}^{1}$.

In the sticking phase, a linear elastic relation is considered between the variation of stresses and the variation of gap function, such that

$$
\left[\begin{array}{c}
\dot{p}_{N} \\
\dot{\tau_{T}}
\end{array}\right]=\left[\begin{array}{cc}
K_{N} & 0 \\
0 & K_{T}
\end{array}\right]\left[\begin{array}{l}
\dot{g_{N}} \\
\dot{g_{T}}
\end{array}\right]
$$

where $g_{N}$ is the normal component of the gap function, that is, penetration between two bodies in contact, and $g_{T}$ is the tangential component of the gap function. $K_{N}(>0)$ and $K_{T}(>0)$ are the penalty coefficients, which control the tolerated penetration of the contacting bodies and their relative tangential micro displacement within the context of the penalty method. The (contact) stresses are then updated, upon contact, at the end of each time step on the basis of the aforementioned incremental relation (see [2] for further details).

It must be noted that in the case of loss of contact, the tensile stress (i.e., $p_{N}^{0}>0$ ) is not admissible. Instead, the normal component of effective stress is set equal to zero.

Concerning the hydraulic constitutive law, the fluid flux within the interface of two contacting bodies results from the transversal pore water pressure exchange between the two sides of interface, such that

$$
f_{w, t}=\rho_{w} T_{w} \Delta p_{w}
$$

where $\rho_{w}$ is the water specific mass, $T_{w}$ is the transverse transmissivity to which the fluid flux is proportional, and $\Delta p_{w}$ is the local gradient of pore water pressure between two bodies in contact.

The contact interface is discretized by definition of two-dimensional (2D) (zero-thickness) isoparametric finite elements with three nodes. These elements on the interface surface $\Gamma_{c}^{1}$ (Figure 4) are compatible (in nodes) with the solid finite element used to discretize the corresponding body. Given a segment-to-segment contact approach, there are three-node segments on the other side $\left(\Gamma_{c}^{2}\right)$ compatible with the corresponding solid finite element. The nodal unknowns on each side of the interface unify with those on the corresponding body's contacting surface. The quadratic interpolation functions are used to interpolate hydraulic pore water pressure and mechanical coordinates over the interface elements [18]. Further details on the finite element formulation employed for these elements are out of the scope of the current study, interested readers may refer to $[2,5,19]$.

\subsection{Constitutive models: rock and concrete behavior}

Given the porous structure of geomaterials and the saturated conditions, an assembly of the solid skeleton and fluid phase (water) is taken into account [20] where mass transfers occur [21]. 
Terzaghi's postulate is assumed to define the effective stress $\sigma_{i j}^{\prime}$ (with compressive stress taken as negative), which engenders the deformation of the solid skeleton in rock, relative to total stress on the bulk material $\sigma_{i j}$ and the water pressure field $p_{w}$ :

$$
\sigma_{i j}^{\prime}=\sigma_{i j}+p_{w} \delta_{i j}
$$

where $\delta_{i j}$ is the Kronecker symbol.

Within the context of elasto-plasticity, the Drucker-Prager frictional yield limit governs the rock behavior:

$$
F \equiv I I_{\hat{\sigma}}+m\left(I_{\sigma}-\frac{3 c}{\tan \varphi_{c}}\right)=0
$$

where $I I_{\hat{\sigma}}$ is the second deviatoric stress invariant given by

$$
I I_{\hat{\sigma}} \equiv \sqrt{\frac{1}{2} \hat{\sigma}_{i j} \hat{\sigma}_{i j}} \quad ; \quad \hat{\sigma}_{i j}=\sigma_{i j}-\frac{I_{\sigma}}{3} \delta_{i j}
$$

where $\hat{\sigma}_{i j}$ is the deviatoric stress tensor and $I_{\sigma}=\sigma_{i j} \delta_{i j}$ is the first stress invariant.

In addition, $c$ is the cohesion, $\varphi_{c}$ is the compression friction angle, and $m$ is defined by

$$
m=\frac{2 \sin \varphi_{c}}{\sqrt{3}\left(3-\sin \varphi_{c}\right)} .
$$

The hardening/softening of the yield surface in this frictional model is defined through the hyperbolic variations of friction angle and cohesion as the function of the von Mises equivalent plastic strain $\left(\varepsilon_{e q}^{p}\right.$, see Eq. (10)), such that

$$
\begin{gathered}
\varphi_{c}=\varphi_{c, 0}+\frac{\left(\varphi_{c, f}-\varphi_{c, 0}\right) \varepsilon_{e q}^{p}}{B_{\varphi}+\varepsilon_{e q}^{p}}, \\
c=c_{0}+\frac{\left(c_{f}-c_{0}\right) \varepsilon_{e q}^{p}}{B_{c}+\varepsilon_{e q}^{p}},
\end{gathered}
$$

where $\varphi_{c, 0}$ is the initial compression friction angle, $\varphi_{c, f}$ is the final compression friction angle, $c_{0}$ is the initial cohesion, $c_{f}$ is the final cohesion, and $B_{\varphi} / B_{c}$ are the values of equivalent plastic strain for which half of hardening/softening on friction angle/cohesion is achieved.

$$
\varepsilon_{e q}^{p}=\sqrt{\frac{2}{3} \hat{\varepsilon}_{i j}^{p} \hat{\varepsilon}_{i j}^{p}} \quad ; \quad \hat{\varepsilon}_{i j}^{p}=\varepsilon_{i j}^{p}-\frac{\varepsilon_{k k}^{p}}{3} \delta_{i j}
$$

In addition, the material cross-anisotropy is considered for the rock given its sedimentary nature and the mode of deposition. Thus, its deformation characteristics due to excavation are considered to be direction dependent. To do this, an extension of the Drucker-Prager model is used and integrated with the elastic and plastic cross-anisotropy. The cross-anisotropic elasticity of the material is taken into account through the compliance elastic matrix $[22,23]$ so that the behavior is considered to be isotropic in the plane of bedding and anisotropic perpendicular to the bedding (see [2] for further information). Regarding the elasto-plastic behavior of the material, [24] has shown that the anisotropy of strength and failure plane inclination of sedimentary rocks vary with respect to the angle between the bedding plane and major principle stress. The author has also indicated that the material cohesion has an essential impact on the mode of deformation and strength parameters of 
the material. Therefore, the plastic anisotropy is taken into account through the material cohesion so that the initial and final cohesions are given by [25]:

$$
\begin{aligned}
& c_{0 \text { or } f}=\max \left[\left(\frac{c_{0 \text { or } f\left(45^{\circ}\right)}-c_{0 \text { or } f\left(0^{\circ}\right)}}{45^{\circ}}\right) \alpha_{\sigma_{1}}+c_{0 \text { or } f\left(0^{\circ}\right)} ;\right. \\
& \left.\left(\frac{c_{0 \text { or } f\left(90^{\circ}\right)}-c_{0 \text { or } f\left(45^{\circ}\right)}}{45^{\circ}}\right)\left(\alpha_{\sigma_{1}}-45^{\circ}\right)+c_{0 \text { or } f\left(45^{\circ}\right)}\right]
\end{aligned}
$$

where the cohesion (initial/final) is defined depending on the angle between major principle stress and the normal vector to the bedding plane, $\alpha_{\sigma_{1}}$. Then, the cohesion is assumed to be linearly varied in function of the angle $\alpha_{\sigma_{1}}$, between three cohesion values which are defined in the model for $\alpha_{\sigma_{1}}=0^{\circ}, \alpha_{\sigma_{1}}=45^{\circ}$, and $\alpha_{\sigma_{1}}=90^{\circ}$.

Concerning the concrete behavior, a simple elastic constitutive law expresses the relation between the total stress and strain field, as follows:

$$
\sigma_{i j}=C_{i j k l}^{e} \varepsilon_{k l}
$$

where $C_{i j k l}^{e}$ is a fourth-order elasticity tensor.

\subsection{Coupled second grade governing equations}

Within the framework of the finite element method, the governing equations are subsequently described as needed. Given the numerical modeling of strain localization in rock, as addressed in Section 6, the classical finite element suffers from a pathological problem of mesh dependency. As a result, the localization zone (the bands thickness) depends on the size of the mesh used for spatial discretization. Hence, a specific approach, introducing a length scale, is needed to overcome this problem in order to properly model the localization phenomenon and post-localization behavior. In this study, the prediction of our material response in the presence of strain localization is regularized in the framework of microstructure continuum theory, using the local second gradient method [26-29] for a two-phase saturated medium [30]. The kinematics thence include macrokinematics as well as microkinematics. Consequently, a microkinematic gradient field $v_{i j}$ is defined to describe strain and rotation at the microscale. Additional terms are then added to the classical continuum mechanics through the internal virtual work of a given body. Therefore, for every kinematically admissible virtual displacement field $u_{i}^{\star}$ and virtual microkinematic gradient field $v_{i j}^{\star}$, the internal and external virtual work expressions in the weak form must be equal, following the principle of virtual work:

$$
\mathcal{W}_{I}^{\star}=\mathcal{W}_{E}^{\star}
$$

Then, we have

$$
\int_{\Omega}\left(\sigma_{i j} \frac{\partial u_{i}^{\star}}{\partial x_{j}}+\tau_{i j}\left(v_{i j}^{\star}-F_{i j}^{\star}\right)+\Sigma_{i j k} h_{i j k}^{\star}\right) d \Omega=\int_{\Gamma_{\sigma}}\left(\bar{t}_{i} u_{i}^{\star}+\bar{T}_{i} D u_{i}^{\star}\right) d \Gamma,
$$

where $u_{i}^{\star}$ is the virtual displacement field, $\tau_{i j}$ is the microstress tensor, which is defined here in addition to the classical macrostress $\sigma_{i j}$ and is associated to the microstructures, $F_{i j}^{\star}=\partial u_{i}^{\star} / \partial x_{j}$ is the virtual macrodeformation gradient, $\Omega$ is the current solid configuration (volume), $\bar{T}_{i}$ is an external (double) force per unit area in addition to $\bar{t}_{i}$ as the external (classical) traction forces per unit area, and both are applied on the $\Gamma_{\sigma}$ part of the boundary of $\Omega . D u_{i}^{\star}$ is the normal derivative of $u_{i}^{\star}$ and $\Sigma_{i j k}$ is the double stress, the dual of the virtual (micro) second gradient $h_{i j k}^{\star}\left(=\partial v_{i j}^{\star} / \partial x_{k}\right)$. The double stress needs an additional constitutive law, and it is defined within an elastic law [26] as a function of the (micro) second gradient of the virtual displacement. This second gradient law depends on one elastic parameter $D$ to which the shear band width is proportional [28].

Moreover, it is assumed that the microkinematic gradient is equal to the macrodeformation gradient $\left(v_{i j}=F_{i j}\right)$, and consequently, the virtual microkinematic gradient is equal to the virtual 
macrodeformation gradient $\left(v_{i j}^{\star}=F_{i j}^{\star}\right)$. Introducing these assumptions through a field of Lagrange multipliers $\lambda_{i j}$ [28], the balance equation of the local second gradient model within the framework of the principle of virtual work reads

$$
\begin{gathered}
\int_{\Omega}\left(\sigma_{i j} \frac{\partial u_{i}^{\star}}{\partial x_{j}}+\Sigma_{i j k} \frac{\partial v_{i j}^{\star}}{\partial x_{k}}\right) d \Omega-\int_{\Omega} \lambda_{i j}\left(\frac{\partial u_{i}^{\star}}{\partial x_{j}}-v_{i j}^{\star}\right) d \Omega=\int_{\Gamma_{\sigma}}\left(\bar{t}_{i} u_{i}^{\star}+\bar{T}_{i} v_{i k}^{\star} n_{k}\right) d \Gamma, \\
\int_{\Omega} \lambda_{i j}^{\star}\left(\frac{\partial u_{i}}{\partial x_{j}}-v_{i j}\right) d \Omega=0,
\end{gathered}
$$

where $n_{k}$ is the normal vector to the boundary portion $\Gamma_{\sigma}$.

Furthermore, the mass balance expression for the fluid phase (water) is given as Eq. (17), for every kinematically admissible virtual pore water pressure field $p_{w}^{\star}$, to accomplish the aforementioned local second gradient formulation for a coupled hydro-mechanical analysis [30]. In this extension, it has been assumed that the fluid has no influence at the microstructure level, and the double stress $\Sigma_{i j k}$ has then no link with the pore water pressure.

$$
\int_{\Omega}\left(\dot{S} p_{w}^{\star}-m_{i} \frac{\partial p_{w}^{\star}}{\partial x_{i}}\right) d \Omega=\int_{\Omega} Q p_{w}^{\star} d \Omega-\int_{\Gamma_{q}} \bar{q} p_{w}^{\star} d \Gamma
$$

where $\dot{S}$ is the time derivative of the water mass inside $\Omega, m_{i}$ is the water mass flow (Eq. (18)), $Q$ is a sink term, and $\bar{q}$ is the input water mass per unit area prescribed on the boundary portion $\Gamma_{q}$.

Water motion in an anisotropic porous medium is governed by the general Darcy's law, regarding which the water mass flow is expressed by

$$
m_{i}=-\rho_{w} \frac{k_{w, i j}}{\mu_{w}}\left(\frac{\partial p_{w}}{\partial x_{j}}\right) ; \quad \quad i, j=1,2,
$$

where $\rho_{w}$ is the specific mass of water, $k_{w}$ is the intrinsic water permeability, and $\mu_{w}$ is the water dynamic viscosity.

Equations (15-16) and Eq. (17) are held for any time $t$ while the virtual quantities in these equations are dependent on the time $t$.

The spatial discretization of the linearized form of the field equations (15-17) is performed using the finite element method through definition of 2D plane strain isoparametric finite elements (Figure 5). These quadrilateral elements have eight nodes for the displacement and pore pressure

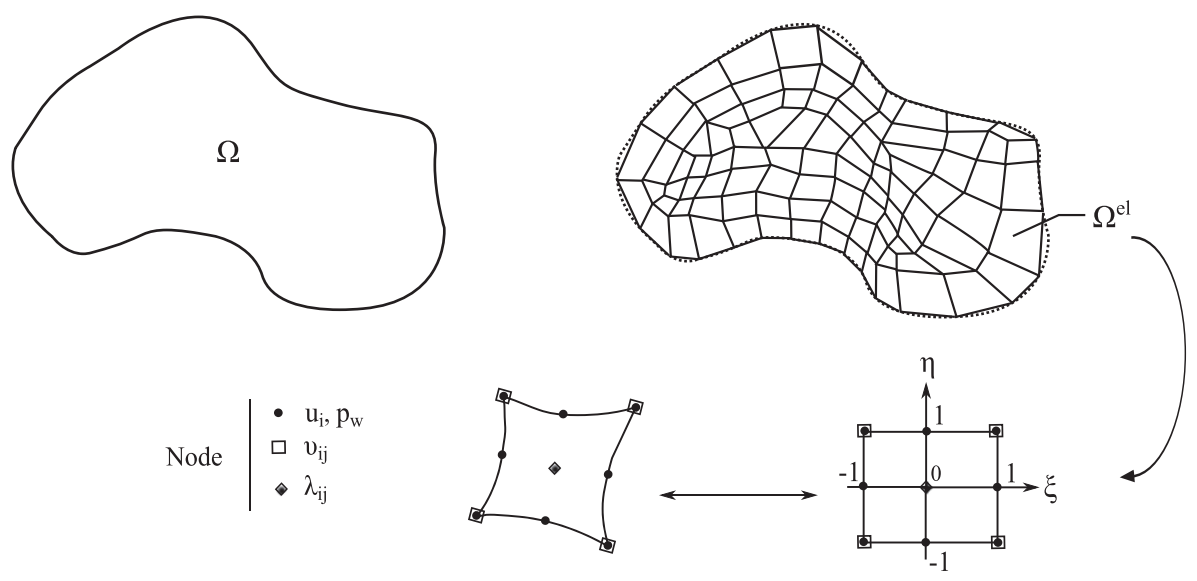

Figure 5. Discretization of the domain $\Omega$ to two-dimensional second gradient finite elements; a quadrilateral two-dimensional second gradient element and the corresponding parent element are shown (bottom). 


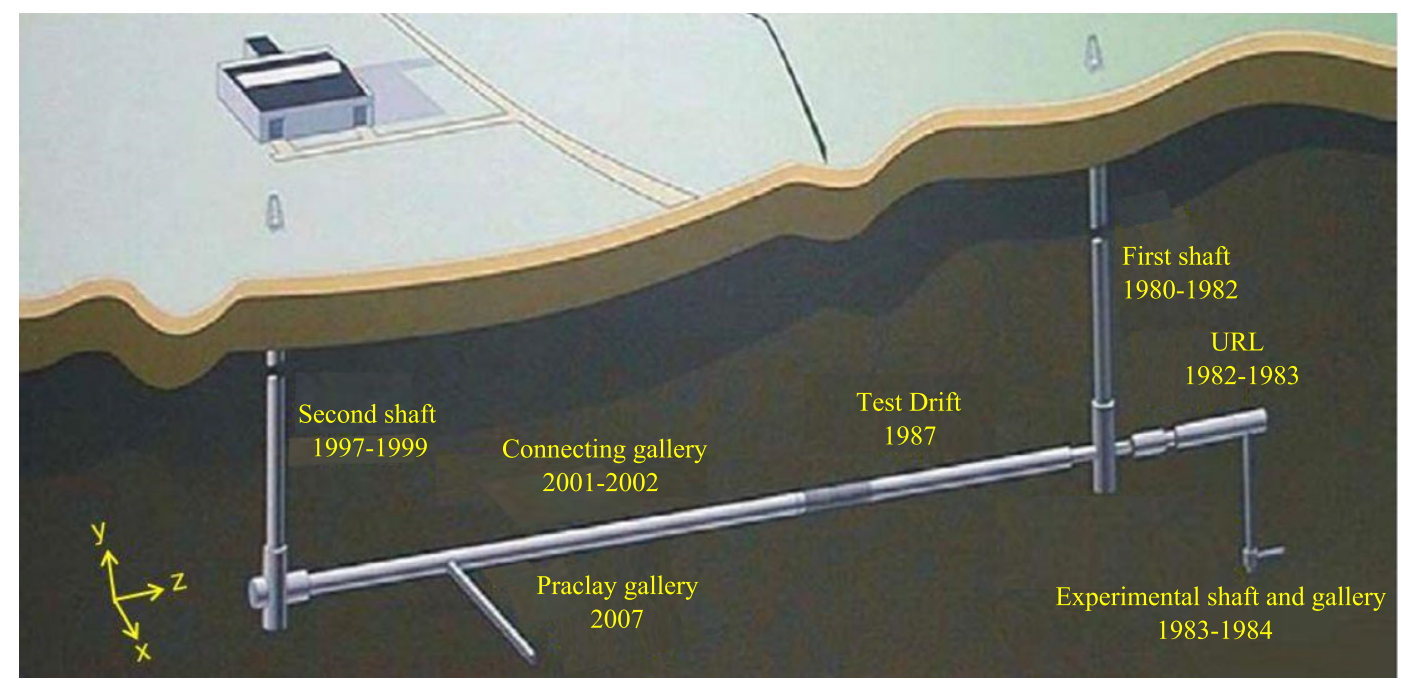

Figure 6. Sketch of different galleries in HADES Underground Research Laboratory (URL), with their excavation dates [3].

fields $\left(u_{i}\right.$ and $\left.p_{w}\right)$, four nodes for $v_{i j}$, and one node for $\lambda_{i j}$. The quadratic shape functions [18] are applied for the $u_{i}$ and $p_{w}$ interpolation, whereas the linear shape functions are used for $v_{i j}$, and $\lambda_{i j}$ is supposed to be constant. Interested readers may refer to $[2,29,30]$ for the detailed coupled finite element scheme.

\section{STUDIED GALLERY}

To study the feasibility of deep disposal of high-level radioactive waste in the Boom clay formation, the HADES Underground Research Laboratory was constructed at a depth of about $225 \mathrm{~m}$ close to the city of Mol, Belgium, in 1980. Since then, different projects have been conducted following the excavation of some galleries (Figure 6). Our focus in this paper is on Connecting gallery, one of the main galleries in HADES.

The industrial excavation technique chosen for Connecting gallery to minimize the extension of the EDZ was to use a tunneling machine consisting of a road header under the protection of a shield. A minimum construction rate of $2 \mathrm{~m}$ per day (between 2 and $4 \mathrm{~m}$ per day) could be achieved in the steady state. The nominal external diameter of the lining is $4.8 \mathrm{~m}$, while the lining thickness is $40 \mathrm{~cm}$. However, a total radial convergence of $9 \mathrm{~cm}$ has been estimated for the clay during the construction [3]. This over-excavation is attributed to the convergence of the clay in the unsupported zone between the rear end of the shield and the installed lining $(1 \mathrm{~cm})$, at the level of the rear end of the shield $(3.5 \mathrm{~cm})$, and ahead of the excavation front $(4.5 \mathrm{~cm})$.

The installation of the gallery's concrete lining was performed quite simultaneously with the gallery excavation. The wedge-block technique has been applied for the lining. The concrete segments were assembled to form rings, which were then expanded against the excavated clay massif through insertion of one or more key segments [3]. The concrete rings of the Connecting gallery's lining include 10 segments each, in addition to two key segments (Figure 1).

\section{ANALYSIS OF THE STRAIN EVOLUTION IN THE GALLERY LINING}

To validate the numerical simulation of the gallery lining response, we refer to the strain measurements of the lining taken since its installation in 2002, provided to us by the EIG EURIDICE. In the following, these measurements are analyzed. They are then compared with the numerical results of the gallery excavation, considering a continuous body for the lining. 


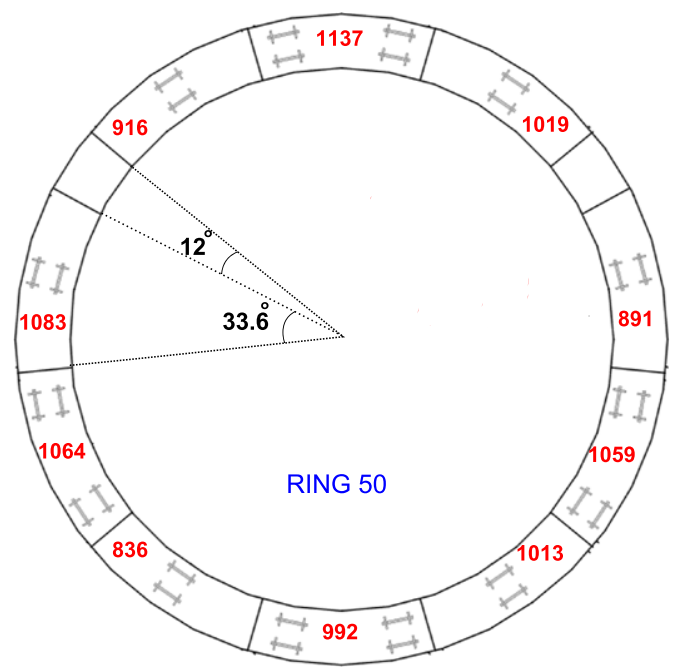

Figure 7. Instrumented ring 50 of the lining [31].
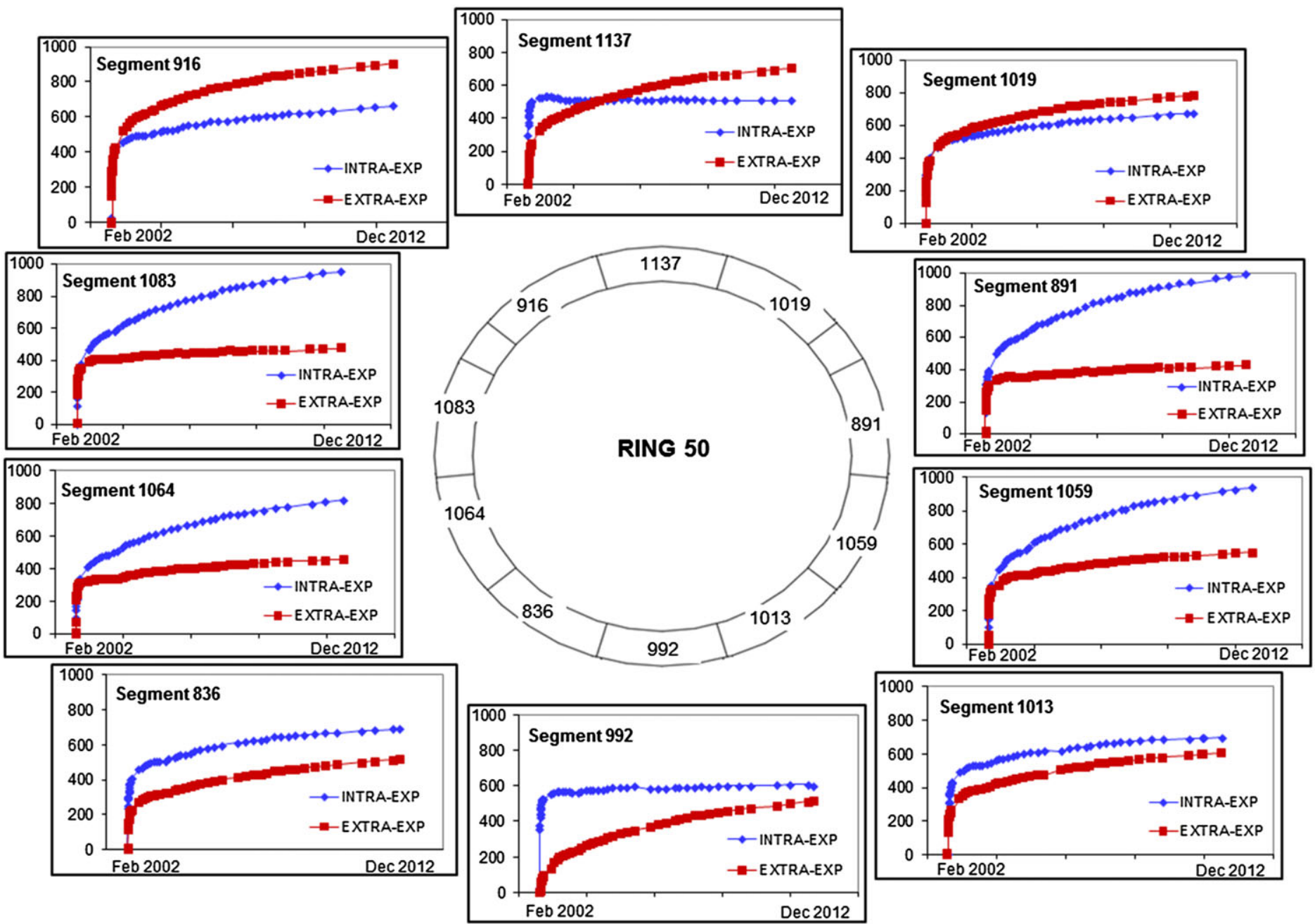

Figure 8. In situ strain measurements $\left(\times 10^{-6},[-]\right)$ in ring 50 of the lining as a function of time. 


\subsection{In situ measurements}

Thanks to the instrumentation in three rings of the Connecting gallery lining as part of the CLIPEX program [31], the strain evolution could be monitored. In this paper, we focus on analysis of the strain measured in the intermediate ring 50 , which has been monitored more frequently, particularly before and after the construction of the ring, according to [31]. Figure 7 shows the configuration of the instrumented segments in this ring.

Figure 8 presents the strain measured by the sensors along the intrados and extrados of all segments of ring 50 since the installation of the ring in February 2002. The first point with regard to the monitored strain evolution is an observed similar strain trend, that is, compressive deformation, recorded by the sensors along both intrados and extrados of each segment. In fact, as presented in [4], an oval-shaped anisotropic deformation of the rock, in interaction with the lining, occurs because of the excavation (Figure 9). Therefore, this long-term compression pattern of strain in the intrados and extrados in all the ring's segments (and similarly in all the lining rings) might be questionable. This aspect is indeed associated to the joints between the segments. These joints do not allow a tension transition between the concrete segments.

Moreover, it is noticed that in the right and left segments (i.e., segments 891, 1059, 1083, and 1064), there is more strain rate in the intrados than the extrados. This pattern is quite contradictory in the top and bottom segments, especially in segments 1137 and 992. Indeed, the pattern of strain evolution in the lining in the long term is linked to the deformation of the clay during the time after its oval-shaped deformation in the course of excavation and the ring installation. The clay tends to an equilibrium and recompression after its contact with the lining (i.e., after the installation of the ring after which the strain has been monitored). Hence, the horizontal diameter of the ring is supposed to be increased in the long-term - which lies in the higher (rate) compressive strain in the corresponding sensors along the lining intrados - on the contrary to its vertical diameter (Figure 17).

\subsection{Numerical modeling considering a continuous lining}

A quarter of the studied gallery is modeled, in a plane strain condition, by assuming the symmetry along $x$ and $y$ axes. The 2D geometry of the model is shown in Figure 10, considering a continuous body for the gallery lining. An initial $9 \mathrm{~cm}$ of the gap (over-excavation) has been considered between the rock and the lining, as described in Section 3. The initial boundary conditions have also been indicated in Figure 10. The constrained normal derivatives correspond to the definition of the symmetry of radial displacements around the symmetric boundaries (i.e., $\partial u_{x} / \partial y=0$ along the $x$ axis and $\partial u_{y} / \partial x=0$ along the $y$ axis), with respect to [32].

The initial anisotropic stresses and material anisotropy are considered in the model. The anisotropic total stresses, based on the in situ measurements, are applied as $\sigma_{y y}=4.5 \mathrm{MPa}$ and $\sigma_{x x}=3.8475 \mathrm{MPa}$. These stresses are then linearly released on the gallery wall to the atmospheric pressure during 6 days of excavation phase. This progressive release is aimed at accounting for three-dimensional impact of the excavation front in its proximity in our 2D simulation. Afterwards, the atmospheric stresses on the gallery wall remain constant for the rest of the simulation, for about

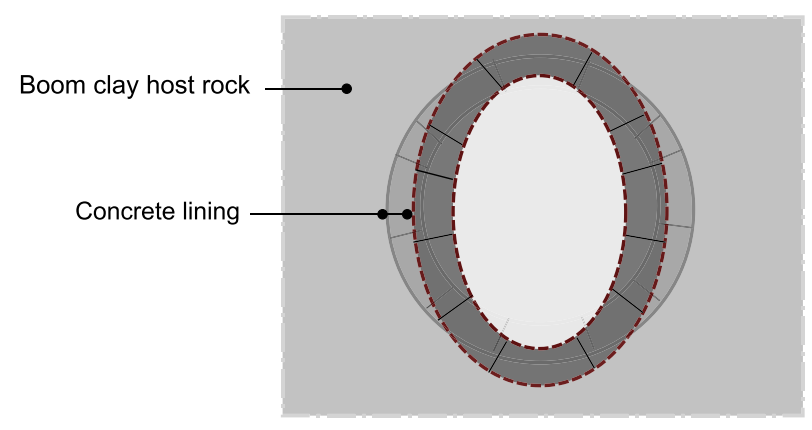

Figure 9. Schematic representation of the oval-shape deformation of the rock in the course of excavation. The lining is assumed to be in place, stuck to the deforming rock. 
11.7 years. Moreover, an initial pore water pressure of $2.25 \mathrm{MPa}$ is defined on the basis of the site measurements. This pressure is also released on the gallery wall to the atmospheric pressure during the excavation phase, providing the null effective stresses. Given that the contact of clay and lining is supposed to occur during the so-called excavation phase (Section 6) following the rock convergence, the (atmospheric) pore pressure is kept constant only on the internal surface of the lining since then.

Tables I-III introduce the model parameters for Boom clay, interface (between lining and rock), and concrete lining. These parameters are mainly defined on the basis of the extensive study performed in the first author's $\mathrm{PhD}$ thesis [2]. In this, the clay parameters have been calibrated on the basis of some experimental results and with respect to the basic investigation given in [33]. Additionally, a specific parametric study has been conducted in [2] to better choose the corresponding parameters in the presence of strain localization. Furthermore, in a hydraulic point of view, the anisotropic permeabilities are given for Boom clay in Table I, based on past studies [34]. These permeabilities are imposed differently in the model during the time after the excavation phase on the basis of the in situ measurements. Considering that the focus of this paper is principally on the lining behavior, further details on this aspect are out of scope of the current study and may be found in [2] upon interest.

Referring to segment 891 (Figure 7) as an example, the response of the continuous lining in our numerical analysis is presented in comparison to site measurements in Figure 11. First and foremost, both the compressive and tensile strains are numerically predicted contrary to the measurements. Nevertheless, a compressive response for the sensor along the intrados of segment 891 is realistically predicted with respect to the long-term deformation pattern of the lining and the rock in contact.

\subsection{Discussion}

The numerical prediction of both the compressive and tensile strains are shown in Figure 11. This feature is linked to the fact that a continuous lining, without taking into account the jointed concrete blocks, has been considered in our model for the sake of simplicity. As a result, the tension could be transferred between the segments.

Therefore, a fundamental originality of this paper consists in development of the numerical model to take into account a discontinuous lining made of concrete segments (as is the real case, see Figure 1). To do this, interface finite elements are introduced between the segments while a numerical approach is proposed to realistically simulate the phenomena occurring within the lining since its installation. As a result of this development, the difficulties encountered in reproducing the in situ measurements in the gallery lining, as described in Section 4.2, are expected to be overcome.

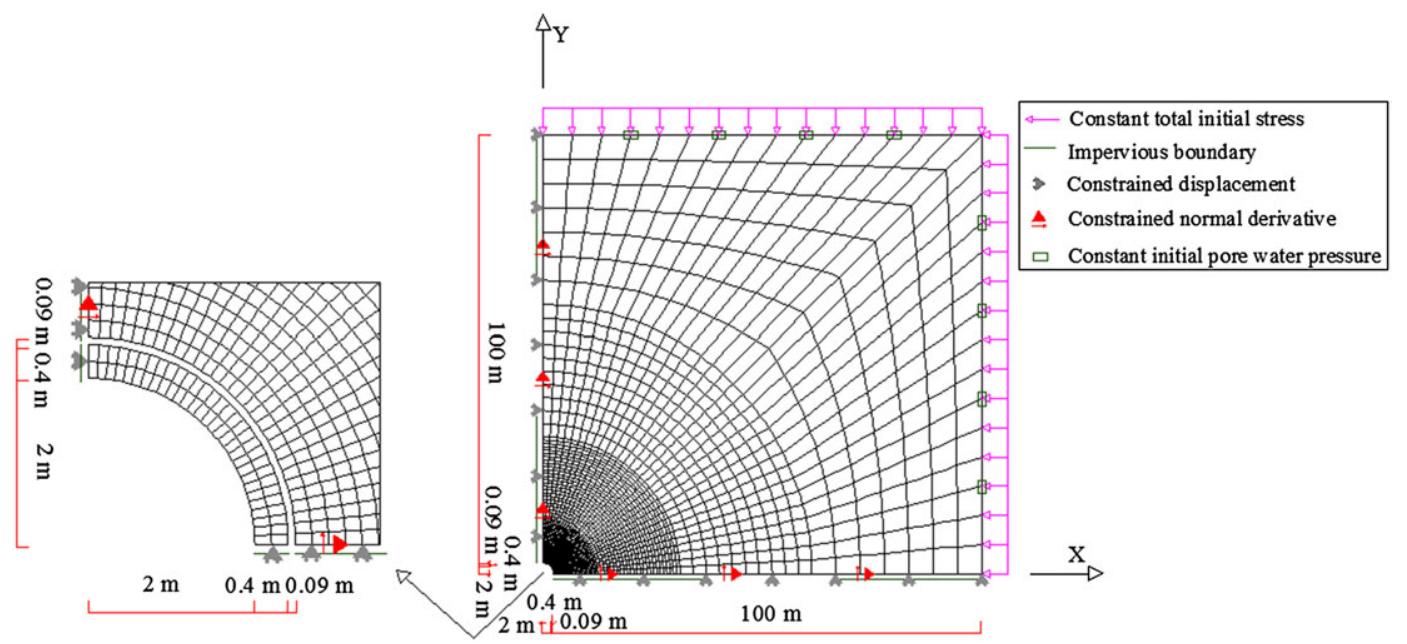

Figure 10. The mesh geometry and boundary conditions of the model. Left: A close-up of the gallery's proximity. 


\section{SIMULATION OF A DISCONTINUOUS LINING BEHAVIOR}

\subsection{Description of the model}

To develop our numerical model to take into account the concrete segments and to simulate the relative phenomena associated to their interfaces, the interface finite element tool is used. The interface elements are defined between the segments of the lining, in addition to the interface between the rock and the lining; see Figure 12. Table IV introduces the parameters given for the three new interfaces. The overall model follows the initial and boundary conditions thus far. Besides, new conditions are needed for the three interfaces defined within the lining, as described in the following.

From the numerical point of view, an initial stability of these discontinuous segments neighboring each other (i.e., in contact; stuck) needs the definition of an initial pressure on their contact interfaces, which restricts their initial movement away from each other. It must be noted that there

Table I. Boom clay properties.

\begin{tabular}{lccc}
\hline Parameter & Symbol & Value & Unit \\
\hline Young elastic modulus & $E \|$ & 400 & $M P a$ \\
Young elastic modulus & $E \perp$ & 200 & $M P a$ \\
Poisson ratio & $\vartheta\|\|$ & 0.125 & - \\
Poisson ratio & $\vartheta \perp \|$ & 0.0625 & - \\
Shear modulus & $G \perp \|$ & 178 & $M P a$ \\
Initial friction angle & $\varphi_{c 0}$ & 8 & $\circ$ \\
Final friction angle & $\varphi_{c f}$ & 18 & $\circ$ \\
Hardening coefficient & $B_{\varphi}$ & 0.001 & - \\
Initial cohesion & $c_{0}\left(0^{\circ}\right)$ & 255 & $k P a$ \\
Initial cohesion & $c_{0}\left(45^{\circ}\right)$ & 240 & $k P a$ \\
Initial cohesion & $c_{0}\left(90^{\circ}\right)$ & 330 & $k P a$ \\
Final cohesion & $c_{f}\left(0^{\circ}\right)$ & 23.18 & $k P a$ \\
Final cohesion & $c_{f}\left(45^{\circ}\right)$ & 21.8 & $k P a$ \\
Final cohesion & $c_{f}\left(90^{\circ}\right)$ & 30 & $k P a$ \\
Softening coefficient & $B_{c}$ & 0.05 & - \\
Second gradient elastic modulus & $D$ & 2000 & $\mathrm{~N}$ \\
Dilatancy angle & $\Psi$ & 0 & $\circ$ \\
Horizontal water permeability & $k_{w, x}$ & $5.06 \times 10^{-19}$ & $\mathrm{~m}^{2}$ \\
Vertical water permeability & $k_{w, y}$ & $2.3 \times 10^{-19}$ & $\mathrm{~m}^{2}$ \\
Specific mass of water & $\rho_{w}$ & $1 \times 10^{3}$ & $\mathrm{Kg} / \mathrm{m}^{3}$ \\
Porosity & $\phi$ & 0.39 & - \\
Water compressibility & $\frac{1}{\chi}$ & $5 \times 10^{-10}$ & $\mathrm{~Pa}-1$ \\
Water dynamic viscosity & $\mu_{w}$ & $1 \times 10^{-3}$ & $\mathrm{~Pa} . \mathrm{s}$ \\
\hline & & & \\
\hline
\end{tabular}

Table II. Interface properties: interface between the rock and the lining.

\begin{tabular}{lccc}
\hline Parameter & Symbol & Value & Unit \\
\hline Penalty coefficient on contact pressure & $K_{N}$ & $3 \times 10^{9}$ & Pa.m $^{-1}$ \\
Penalty coefficient on contact friction & $K_{T}$ & $3 \times 10^{9}$ & Pa.m $^{-1}$ \\
Coulomb friction coefficient & $\mu$ & 0.2 & - \\
Transverse transmissivity & $T_{w}$ & $1 \times 10^{-8}$ & m/Pa.s \\
\hline
\end{tabular}

Table III. Concrete properties.

\begin{tabular}{lccc}
\hline Parameter & Symbol & Value & Unit \\
\hline Young elastic modulus & $E$ & 43,305 & $M P a$ \\
Poisson ratio & $\vartheta$ & 0.25 & - \\
Water permeability & $k_{w}$ & $4 \times 10^{-17}$ & $m^{2}$ \\
Porosity & $\phi$ & 0.15 & - \\
\hline
\end{tabular}


is no contact yet with the rock. A so-called initial contact pressure is then defined for the interface elements corresponding to each of the two neighboring segments (i.e., $p_{N}^{0}<0$ ). This purely numerical-based pressure is given as equal to $-4 \times 10^{7} \mathrm{~Pa}$ on the basis of a parametric study [2].

Assuming that the lining behaves as a cylinder, the equilibrium condition consists in an external pressure $p_{e}$ (Figure 13), which is related to the defined initial pressure between the neighboring

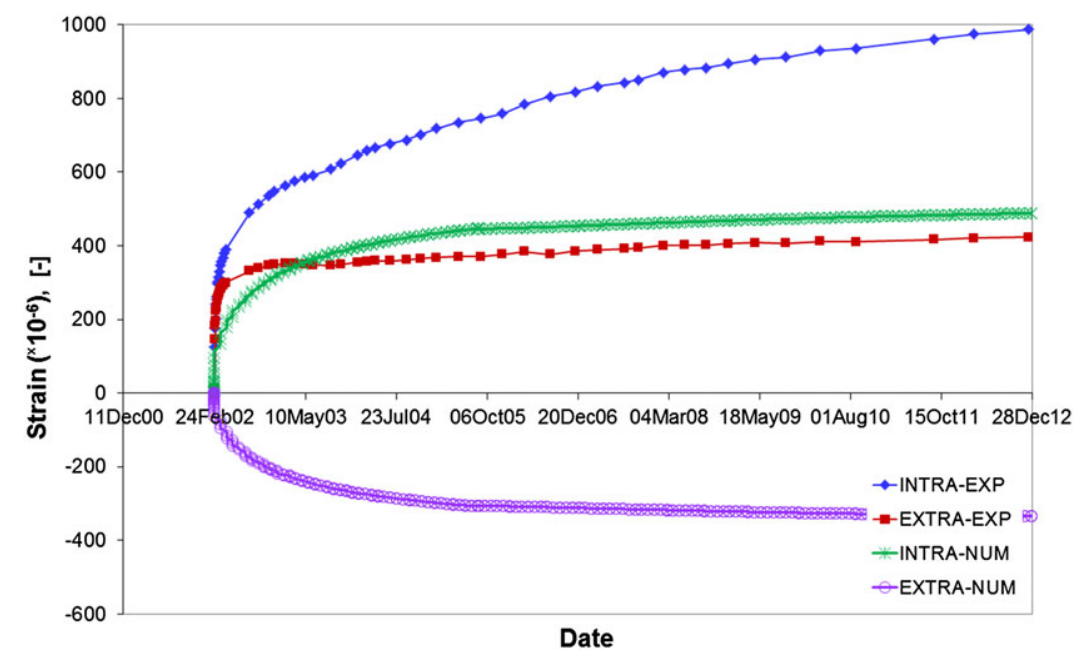

Figure 11. In situ strain measurements in segment 891 of ring 50 of the lining as a function of time, compared with the numerical results considering a continuous lining.

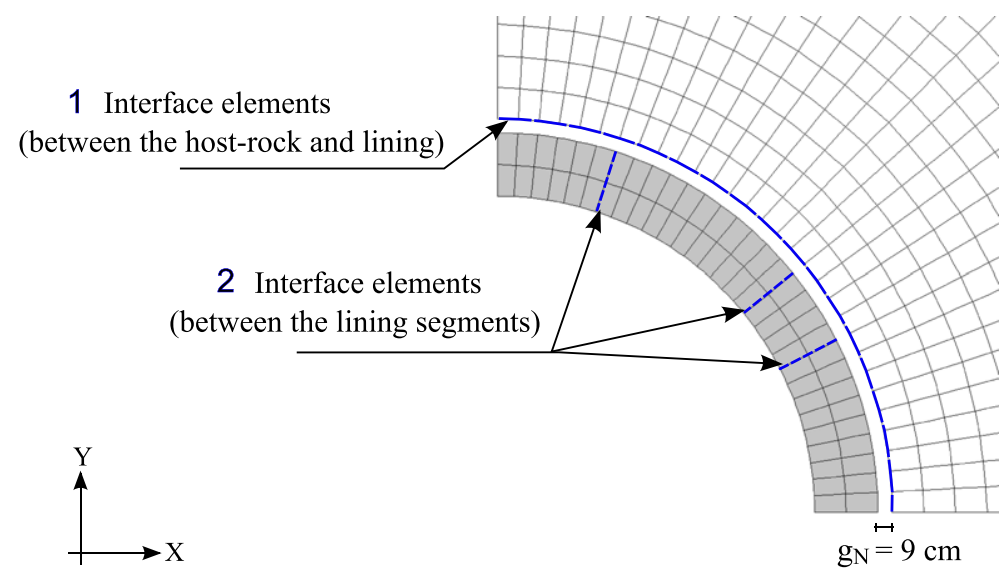

Figure 12. Representation of the interfaces model considering a discontinuous lining. Clay mass (in white) and concrete lining (in gray) are in their no-contact state.

Table IV. Interface properties: interfaces between the lining segments.

\begin{tabular}{lccc}
\hline Parameter & Symbol & Value & Unit \\
\hline Penalty coefficient on contact pressure & $K_{N}$ & $1.8 \times 10^{10}$ & Pa.m $^{-1}$ \\
Penalty coefficient on contact friction & $K_{T}$ & $1.8 \times 10^{10}$ & Pa.m $^{-1}$ \\
Coulomb friction coefficient & $\mu$ & 0.3 & - \\
Transverse transmissivity & $T_{w}$ & $1 \times 10^{-14}$ & m/Pa.s \\
\hline
\end{tabular}


segments - equivalent to the circumferential (hoop) stress $\sigma^{H}$ - through

$$
\sigma^{H}=\frac{p_{i} r_{i}^{2}-p_{e} r_{e}^{2}}{r_{e}^{2}-r_{i}^{2}}-\frac{r_{i}^{2} r_{e}^{2}\left(p_{e}-p_{i}\right)}{r^{2}\left(r_{e}^{2}-r_{i}^{2}\right)},
$$

where $r_{i}$ and $r_{e}$ are the internal and external radii, which are respectively equal to 2 and $2.4 \mathrm{~m} . r$ is the radius at a point in the cylinder (i.e., lining) where the circumferential stress (i.e., initial pressure between the neighboring segments) is addressed, which is considered as $2.2 \mathrm{~m}$ (i.e., mean radius). $p_{i}$ is the internal pressure that is equal to zero here. As a result, the external pressure is obtained as $p_{e}=6.69 \times 10^{6} \mathrm{~Pa}$.

Furthermore, taking this discontinuous lining into account makes our numerical model much more complicated. We have aimed to conduct our approach so that we could simulate to the maximum extent possible the main aspects concerning the lining, with respect to its real installation procedure. Given the installation technique of the 12 segments in each ring of the lining (Figure 14), the process performed is mainly summarized as follows, on the basis of [3]:

(i) Placement of segment 6 on the bottom of the gallery while it is held in place against the corresponding segment ' 6 ' of the previous ring (along the gallery axis) by the thrust pressure of the jacks.

(ii) Placement of segments 7, 5, 4, and 8, in a similar manner to segment 6 .

(iii) Placement of segments 3 and 9.

(iv) Partial insertion of the key segments 11 and 12.

(v) Placement of segments 10, 1, and 2 with an anti-fall system emplaced for each of these three segments.

(vi) Full insertion of the two key segments to their final position, with an expansion of the ring.

The first five steps of the aforementioned procedure relate the overall process of segments placement beside each other. While some pressure could be considered to be produced among the segments, they are in equilibrium with no important violation of their stability. This is supposed to have been integrated within the definition of the initial contact pressure in our numerical approach hitherto. The last step, that is, the full insertion of the key segments, is considered to then produce an extra pressure among the segments, which results in an expansion of the lining ring.

The lining installation has been performed quite simultaneously with the gallery construction (almost immediately after the passage of the excavation front [3]). Hence, this last step (extra) pressure (linked to insertion of the key segments) is regarded, from the numerical point of view, as the pressure exerted between the segments at the end of our so-called excavation phase. Therefore, our numerical approach takes into account an increase of the pressure on the segments' interfaces at the beginning of the second numerical phase (i.e., from the end of the sixth day of excavation) in order to simulate the pressure imposed by the keys' full insertion between the segments.

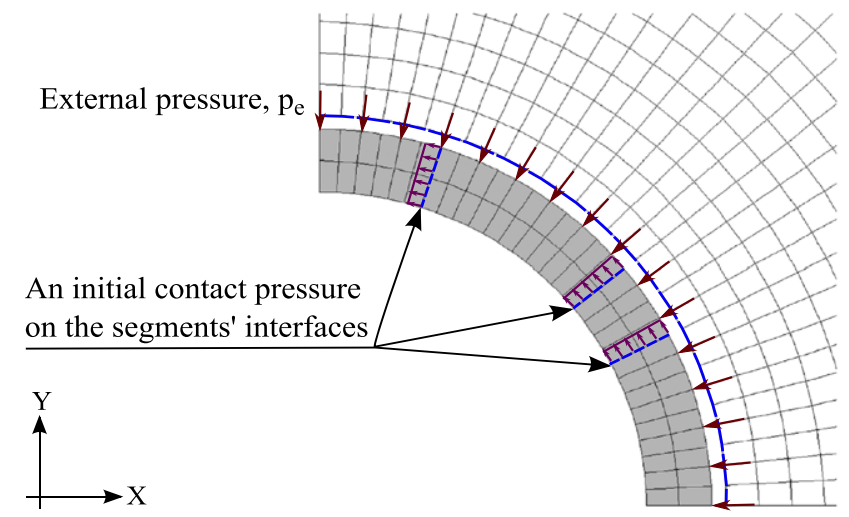

Figure 13. Schematic representation of the initial contact pressure on three contact interfaces and the external pressure on the lining. 
We do not have any direct in situ measurements of the pressure between the segments to be referred in our numerical simulation. The strain measurements within the lining segments (Section 4.1), which are available immediately following the full insertion of the key segments, are the best tool to calibrate our assumption of the pressure produced between the segments through the keys insertion. In this sense, the numerical results of the strain evolution could be checked against the corresponding measurements, and as a result, the appropriateness of our assumption of that pressure considered between the segments could also be verified. Within this framework and through several simulations (with different assumptions), the produced (extra) compressive pressure on the segments' interfaces is estimated as $-1.5 \times 10^{7} \mathrm{~Pa}$ consisting in an external pressure on the lining (with respect to Eq. (19)) equal to $2.51 \times 10^{6} \mathrm{~Pa}$. This assumption is validated in the following section with regard to the strain measurements in the lining.

\subsection{Comparison of the numerical predictions and in situ measurements in the lining}

The strain measurements, as described in Section 4.1, are available from the installation of the ring in February 2002. The first data of the sensors along both the intrados and extrados of each segment have been recorded on the day before and after full key insertion, and thereafter, the measurements have continued over time.

For the presentation of results, the aforementioned procedure is reproduced through presenting the numerical results of strain evolution with reference to one day before the imposition of the extra pressure induced by the key segments (as described in Section 5.1), that is, end of the fifth day of computation, compared with the in situ data.

On the whole, two main features are therefore regarded in the following comparison, through our approach:

(i) An extra pressure, related to the full insertion of the key segments and expansion of the ring, in the last step of the ring installation, is considered on the segments' interfaces in our simulation.

(ii) The comparison between the strain measurements and the corresponding numerical results is performed from one day before the key insertion, reproduced numerically through the aforementioned imposed extra contact pressure.

Figure 15 presents the obtained numerical results compared with the in situ measurements, in segment 891 of ring 50 (Figure 7). This comparison can then be contrasted with the comparison given in Figure 11 on the basis of the assumption of a continuous lining. First and foremost, it is observed that the numerical predictions are principally improved here taking into account the discontinuous lining. As a result, no tension is permitted to be transferred between the segments. Additionally, the immediate increase of the strain at the beginning of the experimental curves, associated to the quick response of the segments after the key insertion (given some pressure produced among the segments), is quite well reproduced by the numerical simulation. This latter could also validate

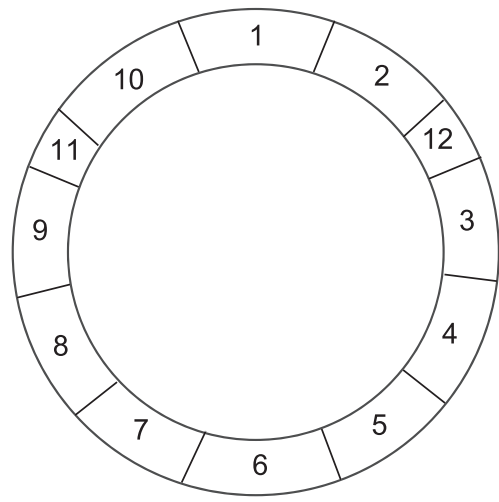

Figure 14. Segment numbering; after [3]. 


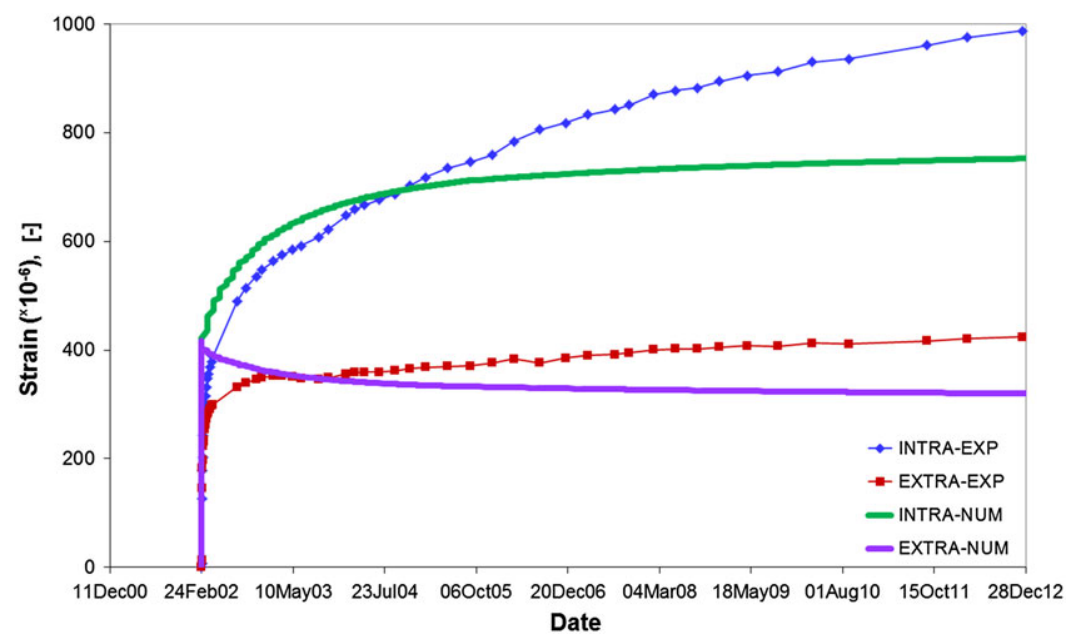

Figure 15. In situ strain measurements in segment 891 of ring 50 of the lining as a function of time, compared with the numerical results considering a discontinuous lining.

the relevancy of our assumption of the applied extra contact pressure on the segments' interfaces corresponding to the keys' full insertion (see the approach described in Section 5.1).

Moreover, the predicted evolution pattern of strain is overall in pretty good agreement with the measurements. Nevertheless, the compressive behavior recorded by the sensor along the intrados of the segment seems to be fairly underestimated over a very long time. This underestimation might be reasonably associated to the creep of concrete, which has not yet been included in our model.

The creep of concrete is integrated here through the diminution of its Young's modulus over time. The effect of this issue on the obtained results has been studied simply through several numerical simulations performed with modification of the concrete Young's modulus over time so that the long-term in situ strain measurements could be better reproduced [2]. Consequently, an estimation of the creep behavior of concrete is considered as follows: the defined initial value of the Young's modulus, that is $43,305 \mathrm{MPa}$ (Table III), is assumed to be diminished to one-third after 2 years (of our analysis), while this latter value is imposed for 1.5 years. Subsequently, the creep behavior of concrete over a longer time (the rest of the simulation, up to 11.7 years) is assumed to consist in an (initial) Young's modulus decreased to one-sixth.

Consequently, Figure 16 represents the final numerical results of the strain evolution in the studied segment, beside the former results (assuming a continuous lining; Figure 11), compared with the relative in situ measurements. It is observed that in addition to the aforesaid main improvement achieved through the developed model with a discontinuous lining, the very long-term behavior of concrete is also upgraded as a result of the modifications of Young's modulus over time. Hence, overall, the corresponding numerical curves over the longer time better approach the experimental curves.

\subsection{Discussion}

The difficulties encountered concerning a correct simulation of lining behavior and in reproducing the corresponding in situ measurements, with the simplistic approach considering a continuous lining, have been overcome through the new development shown here. The achieved improvement is basically due to development of the model to consider the discontinuous lining segments, besides the proposed approach for a more realistic simulation of their interface behaviors. With regard to the technique used for installation of the lining rings in reality, realistically reproducing the pressure induced through the full insertion of the key segments (resulting in an expansion of the rings), in our numerical approach, has been of particular importance. 


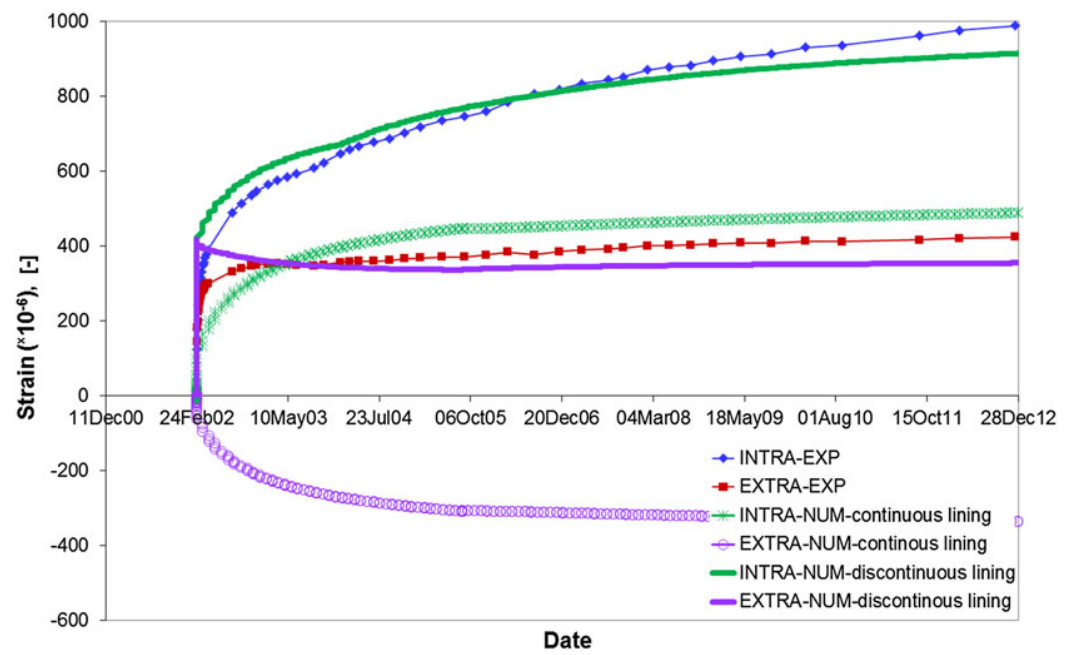

Figure 16. In situ strain measurements in segment 891 of ring 50 of the lining as a function of time, compared with the numerical predictions with two different approaches: considering a continuous or discontinuous lining.

This study is of paramount interest in the framework of studying and simulating the underground deep excavations in Boom clay or within similar host rocks, which fundamentally need the support of lining for tunneling.

\section{ANALYSIS OF CONTACT PHENOMENA BETWEEN THE ROCK AND THE CONCRETE LINING}

Analysis of the lining response has been the focus of this paper, as an open issue of particular interest, because the lining is considered to have an essential role as the foundation for the rock. Therefore, this section is intended to accomplish our study by analyzing the contact mechanism between these two bodies, while the model takes into account a discontinuous lining.

Figure 17 demonstrates the deformation pattern of the model during the simulation time. The initial stability of the model, consisting in the lining segments, is observed as the result of the definition of an initial contact pressure (Figure 18). During the 6 days of the excavation phase, the clay converges towards the lining establishing the contact between the two bodies. As a result of this anisotropic deformation of the clay, an inward horizontal movement of the lining and consequently an upward vertical movement of the lining could be induced, while the lining segments are also relatively moved. In a longer time, a recompression of the clay and an opposite movement of the lining are tended.

With respect to this deformation pattern of the rock, its interaction with the lining is established from the horizontal side, that is, bottom interface elements. Consequently, some contact pressure is produced in that zone, as can be observed in Figure 18 (see the green diagram (after 5 days)). In addition, the contact pressure on the segments' interfaces (blue diagrams) is also evolved from its initial value, with respect to the relative movement manner of the segments.

This contact phenomena between the rock and the lining is then developed on the whole interface between the two bodies at the end of our so-called excavation phase (i.e., 6 days). Therefore, some contact pressure is produced along the corresponding interface.

With regard to Figure 18, some oscillations could be observed in the development pattern of normal contact pressure on the interface. These oscillations, as extensively studied in [2, 4], do not originate in any possible numerical factor. That is to principally say the applied numerical integration scheme, the number of integration points, the numerical discretization of the interface, and defined penalty coefficient. Indeed, this oscillatory type of interface response basically gave birth 
by the development pattern of strain localization in a shear band mode within the rock around the gallery, as presented in [4].

This aspect is illustrated in Figure 19, which presents the superposition of the localized shear bands, in terms of total deviatoric strain and normal contact pressure on the interface between the rock and the lining after 6 days. As can be observed, there is a fundamental accordance between the corresponding two phenomena. Both consist in an anisotropic response of the clay while the peaks of the contact pressure produced on the interface reasonably lie within the larger shear bands.

It may be noteworthy that the pattern of rock response and its interaction with the lining is quite similar to the corresponding obtained pattern considering a continuous body of the lining, with respect to $[2,4,35]$. The differences resulting from the presented numerical development in this paper then mainly address the behavior of the lining, that is, its segments' response and their interaction with each other, as previously discussed.
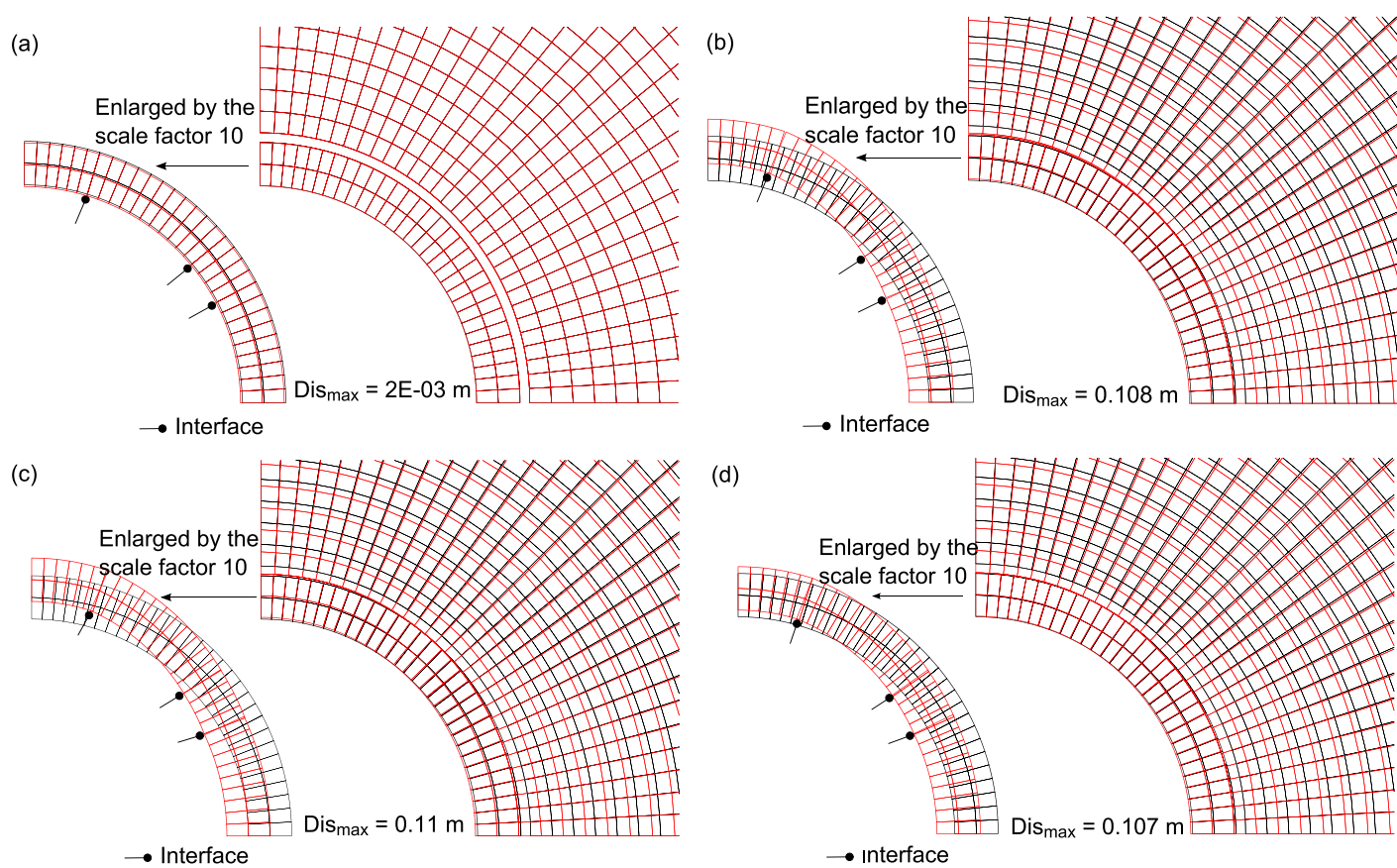

Figure 17. Deformation pattern of the model after (a) $1 \mathrm{~s}$ (beginning of the simulation), (b) 5 days, (c) 6 days, and (d) 11.7 years.

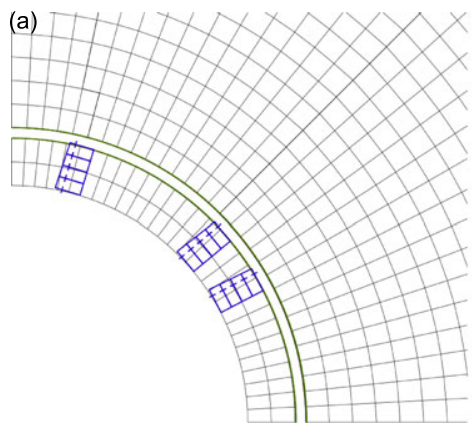

(b) T

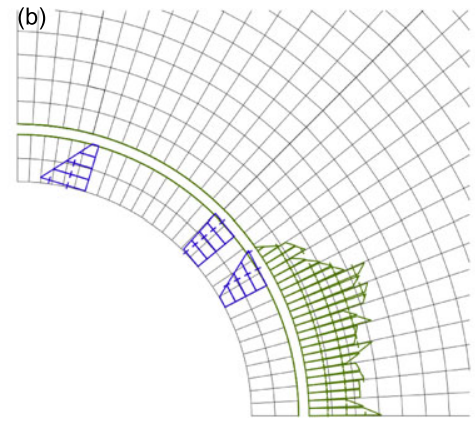

$\longmapsto 3 E 07 \mathrm{~Pa}$

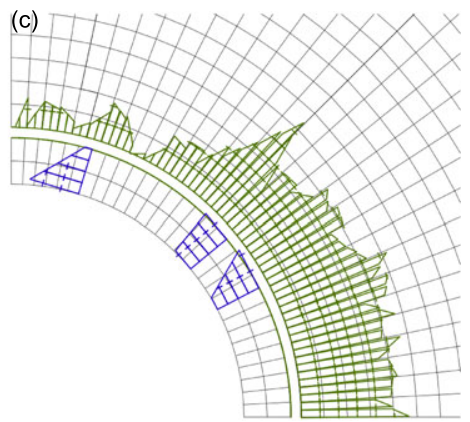

3E05 Pa

Figure 18. Diagram of contact pressure on the interfaces after (a) $1 \mathrm{~s}$ (beginning of the simulation), (b) 5 days, and (c) 6 days. The blue diagrams correspond to the segments' interfaces, and the green diagrams correspond to the interface between the rock and the lining. 


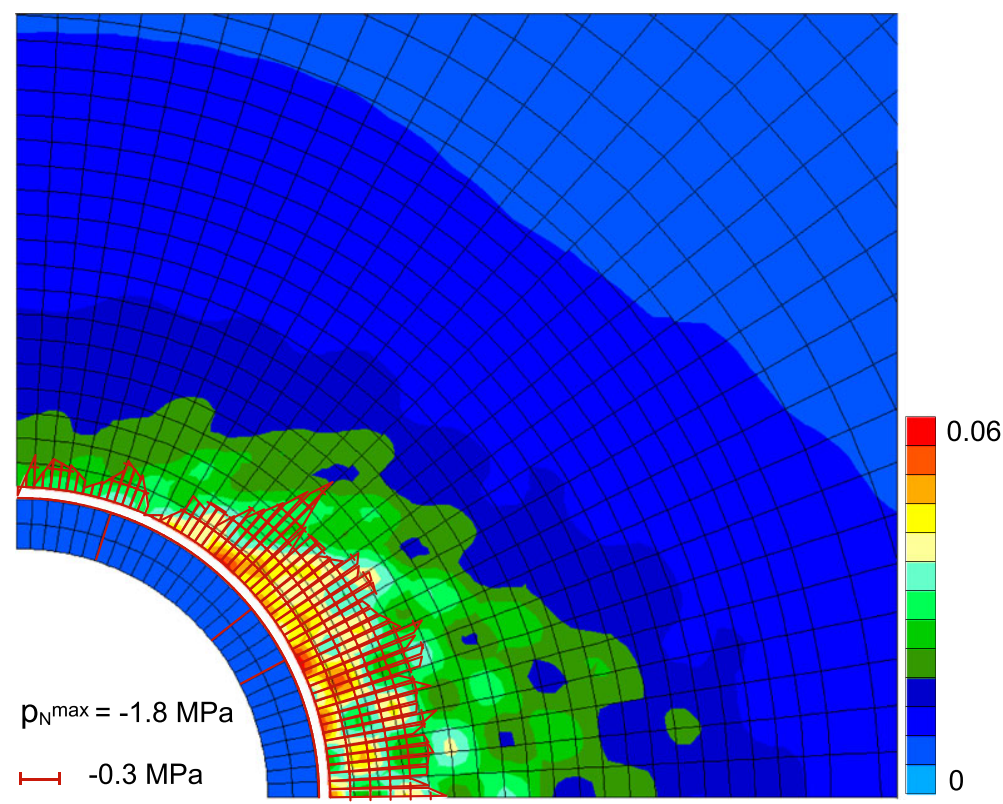

Figure 19. Superposition of the localized shear bands, in terms of total deviatoric strain and normal contact pressure on the interface between the rock and the lining after 6 days.

\section{CONCLUSIONS}

Analysis of the lining behavior while excavating in Boom clay host rock, considering the significant need for gallery lining, is an open issue of particular interest. Given the importance of simulation of the concrete lining's response as the foundation of the clay, and in the framework of deep disposal of high-level radioactive waste through this formation, this issue has been the main focus of this paper in order to fulfill the corresponding gap in the literature and past studies.

Our study has firstly demonstrated the deficiency provided by a simplistic model of a continuous lining, in terms of a realistic simulation of the phenomena that occur within a discontinuous lining made of the concrete blocks. To do this, some available in situ measurements of strain taken in different segments of our studied gallery's lining, in the long term, have been analyzed. Our primary numerical results, considering a continuous lining, have then been discussed against those measurements illustrating the need to develop the numerical model.

A developed model has therefore been presented in this paper proposing an approach that could realistically simulate the behavior of a discontinuous lining. The contact phenomena between the concrete segments of the lining, as well as the contact between the lining and the rock, have been studied through definition of zero-thickness interface elements. The results of the developed model have been analyzed in comparison with the aforesaid in situ measurements. This analysis has then demonstrated the reliability of the proposed approach.

In addition, the deformation pattern of the segments in contact and their relative movement have been numerically presented. Moreover, the contact mechanism between the entire lining and the rock has been demonstrated to be fundamentally in relation with the development of the localized shear band, created due to excavation, within the clay in the gallery's proximity.

\section{ACKNOWLEDGEMENTS}

The Belgian National Agency for Radioactive Waste and enriched Fissile Material, ONDRAF/NIRAS, is gratefully acknowledged for its financial support of the work presented in this paper. This work is part of the first author's PhD thesis. 


\section{REFERENCES}

1. Salehnia F, Charlier R, Levasseur S. Numerical modelling of the excavated damaged zone in Boom clay. International EAGE Workshop on Geomechanics and Energy, Lausanne, Switzerland, 2013.

2. Salehnia F. From some obscurity to clarity in Boom clay behavior: analysis of its coupled hydro-mechanical response in the presence of strain localization. Ph.D. Thesis, Université de Liège, 2015.

3. Bastiaens W, Bernier F, Buyens M, Demarche M, Li XL, Linotte JM, Verstricht J. The connecting gallery. Technical Report, EURIDICE 2003. Report to European Commission.

4. Salehnia F, Collin F, Li XL, Dizier A, Sillen X, Charlier R. Coupled modeling of excavation damaged zone in boom clay: strain localization in rock and distribution of contact pressure on the gallery's lining. Computers and Geotechnics 2015; 69:396-410.

5. Charlier R. Approche unifiée de quelques problèmes non linéaires de mécanique des milieux continus par la méthode des éléments fini. Ph.D. Thesis, Université de Liège, 1987.

6. Collin F. Couplages thermo-hydro-mécaniques dans les sols et les roches tendres partiellement saturés. Ph.D. Thesis, Université de Liège, 2003.

7. Mertens J, Bastiaens W, Dehandschutter B. Characterisation of induced discontinuities in the Boom clay around the underground excavations (URF, Mol, Belgium). Applied Clay Science 2004; 26(1):413-428.

8. Salehnia F, Charlier R, Sillen X, Dizier A. Modeling of excavation damaged zone through the strain localization approach in Boom clay. Computer Methods and Recent Advances in Geomechanics, CRC Press, Kyoto, Japan, 2014; 335.

9. Pardoen B, Seyedi DM, Collin F. Shear banding modelling in cross-anisotropic rocks. International Journal of Solids and Structures 2015; 72:63-87.

10. Charlier R, Collin F, Pardoen B, Salehnia F. Numerical modelling of shear banding around openings in clayey rocks. Application to URL dedicated to nuclear waste disposals. International Symposium on Energy Geotechnics (1st.: 2015: Barcelona): Universitat Politècnica de Catalunya. Departament d'Enginyeria del Terreny, Cartogràfica i Geofísica, Barcelona, Spain, 2015.

11. Pardoen B, Collin F. Modelling the influence of strain localisation and viscosity on the behaviour of underground drifts drilled in claystone. Computers and Geotechnics 2017; 85:351-367.

12. Salehnia F, Collin F, Charlier R. On the variable dilatancy angle in rocks around underground galleries. Rock Mechanics and Rock Engineering 2016; 50(3):587-601. https://doi.org/10.1007/s00603-016-1126-6.

13. TIMODAZ. Large scale excavation and heater in-situ experiment: the PRACLAY experiment modelling. Technical Report WP 5.2, D13, Commision of the Europeen Communities, 2010. Editor: Charlier, R.

14. Salehnia F, Charlier R, Levasseur S. Modeling of strain localization around the radioactive waste disposal galleries. Coupled Phenomena in Environmental Geotechnics, CRC Press, Turin, Italy, 2013; 443.

15. Schellekens J-C-J, De Borst R. On the numerical integration of interface elements. International Journal for Numerical Methods in Engineering 1993; 36(1):43-66.

16. Wriggers P. Computational Contact Mechanics, Vol. 30167. Springer, 2006.

17. Curnier A. A theory of friction. International Journal of Solids and Structures 1984; 20(7):637-647.

18. Zienkiewicz OC, Taylor RL. The Finite Element Method: Solid Mechanics, Vol. 2. Butterworth-heinemann, 2000.

19. Charlier R, Collin F, Gerard P, Radu JP. Développement d'un modèle (element fini et loi de comportement) de fracture couple mécanique -écoulement en saturation partielle. Technical Report, Université de Liège: Liege, 2009.

20. Coussy O, Ulm F. Mechanics of Porous Continua, Vol. 1016. Wiley Chichester, 1995.

21. Gawin D, Baggio P, Schrefler BA. Coupled heat, water and gas flow in deformable porous media. International Journal for Numerical Methods in Fluids 1995; 20(8-9):969-987.

22. Lekhnitskii SG, Fern P. Theory of Elasticity of an Anisotropic Elastic Body. Holden-Day, 1963.

23. Graham J, Houlsby GT. Anisotropic elasticity of a natural clay. Géotechnique 1983; 33(2):165-180.

24. Donath FA. Effects of cohesion and granularity on deformational behavior of anisotropic rock. Geological Society of America Memoirs 1972; 135:95-128.

25. François B, Labiouse V, Dizier A, Marinelli F, Charlier R, Collin F. Hollow cylinder tests on boom clay: Modelling of strain localization in the anisotropic excavation damaged zone. Rock Mechanics and Rock Engineering 2014; 47(1):71-86.

26. Mindlin RD. Micro-structure in linear elasticity. Archive for Rational Mechanics and Analysis 1964; 16(1):51-78.

27. Germain P. La méthode des puissances virtuelles en mécanique des milieux continus. J. Mécanique 1973; 12: 236-274.

28. Chambon R, Caillerie D, El Hassan N. One-dimensional localisation studied with a second grade model. European Journal of Mechanics-A/Solids 1998; 17(4):637-656.

29. Chambon R, Caillerie D, Matsuchima T. Plastic continuum with microstructure, local second gradient theories for geomaterials: localization studies. International Journal of Solids and Structures 2001; 38(46):8503-8527.

30. Collin F, Chambon R, Charlier R. A finite element method for poro mechanical modelling of geotechnical problems using local second gradient models. International Journal for Numerical Methods in Engineering 2006; 65(11): 1749-1772.

31. Bernier F, Li XL, Verstricht J, Barnichon JD, Labiouse V, Bastiaens W, Palut JM, Slimane JKB, Ghoreychi M, Gaombalet J. et al. CLIPEX: Clay instrumentation programme for the extension of an underground research laboratory. Technical Report, EURIDICE 2007. Report EUR 20619 EN to European Commission. 
32. Zervos A, Papanastasiou P, Vardoulakis I. Modelling of localisation and scale effect in thick-walled cylinders with gradient elastoplasticity. International Journal of Solids and Structures 2001; 38(30):5081-5095.

33. Bernier F, Li XL, Bastiaens W. Twenty-five years' geotechnical observation and testing in the tertiary Boom clay formation. Géotechnique 2007; 57(2):229-237.

34. Wemaere I, Marivoet J, Labat S. Hydraulic conductivity variability of the Boom clay in north-east Belgium based on four core drilled boreholes. Physics and Chemistry of the Earth, Parts A/B/C 2008; 33:S24-S36.

35. Salehnia F, Li X, Charlier R. Hydro-mechanical behavior of boom clay host-rock in interaction with a deep excavated gallery's lining. Alert Géomaterials Workshop 2015-Booklet of Abstracts (poster session), Aussois, France, 2015. 